\title{
Photovoltaic Cell Output Voltage Variations with Time and Inclination Angle
}

\author{
Olufemi Olusola Kehinde ${ }^{1}$, Frederick Ojiemhende Ehiagwina ${ }^{2 *}$, Lateef \\ Oroseniwo Afolabi ${ }^{3}$, Olajide Abdulmutolib Olaoye ${ }^{4}$ \\ ${ }_{1,2,3}$ (Department of Electrical/Electronics Engineering, School of Engineering, Federal Polytechnic, Offa, \\ Kwara State, Nigeria) \\ ${ }^{4}$ (Department of Physics Electronics, School of Applied Science, Federal Polytechnic, Offa, Kwara State, \\ Nigeria)
}

\begin{abstract}
The problems with electrical power distribution coupled with its unavailability and uncertainty when urgently needed has led many households to seek alternative sources of energy. An alternative often sought is power generation based on fossil fuel, which is expensive and negatively impact on the environment. Although, solar is favoured as viable source of energy, the output voltage and current from photovoltaic solar panels are not constant but varies with time of day, geographical location and inclination or tilting angle. Therefore, there is a need to experimentally observe these factors influencing solar output in a locality of interest for better solar power system design. In this paper we investigated the best inclination angle for PV panel installation in Offa, North Central Nigeria. We also studied the variation of solar panel voltage and current output with time of day. In order to assist solar power system designer, this article presented typical energy consumption pattern for different income classes. The highest PV voltage output was obtained at 300 - 400. Moreover, from experimental observation of variation of solar PV during a daytime hours over a seven-day period, the highest voltage and current readings were obtained at around 13:00-13:30. We report that the energy consumed by households ranges from $4.423 \mathrm{kWh} /$ day to $46.520 \mathrm{kWh} /$ day.
\end{abstract}

Keywords : Energy consumption, photovoltaic, $P V$ tilt, solar panel, inclination angle, solar radiation

\section{Introduction}

Power generation in Nigeria is inadequate, and energy demand is rapidly increasing. Furthermore, electricity supply from both public and private power supply are not always available and certain. This is in addition to rising cost. Consequently, many households seek alternative sources of energy to make up for the short fall. In addition there is a growing concern for the amount of greenhouse gases emitted to the atmosphere from fossil fuels. However, the preference is for green energy due to their numerous benefits [1]. One benefit of green or renewable energy is that they are sustainable, which implies the use of sustainable energy sources in an efficient manner with minimal environmental impact and better socio-economical acceptance [2,3]. Among the renewable energy sources that can substitute for fossil fuel is hydropower, which on its own have associated negative impacts, such as the problem of flooding susceptibility to seasonal water level fluctuation, and so on. These problems are well discussed in [4]. This thus highlights why solar is favoured as viable source of energy. In addition Nigeria being located in tropical region, have a vast potential of solar energy. This is shown in the solar radiation map shown in Figure 1. The average amount of direct and diffuse solar radiation of Offa, Kwara State North Central Nigeria is shown in Figure 2.

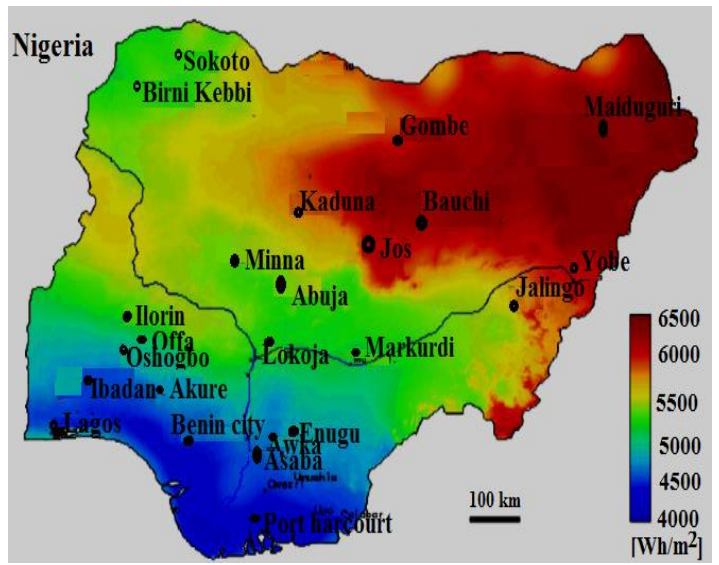

Figure 1: Solar radiation map of Nigeria, adapted from [3] 


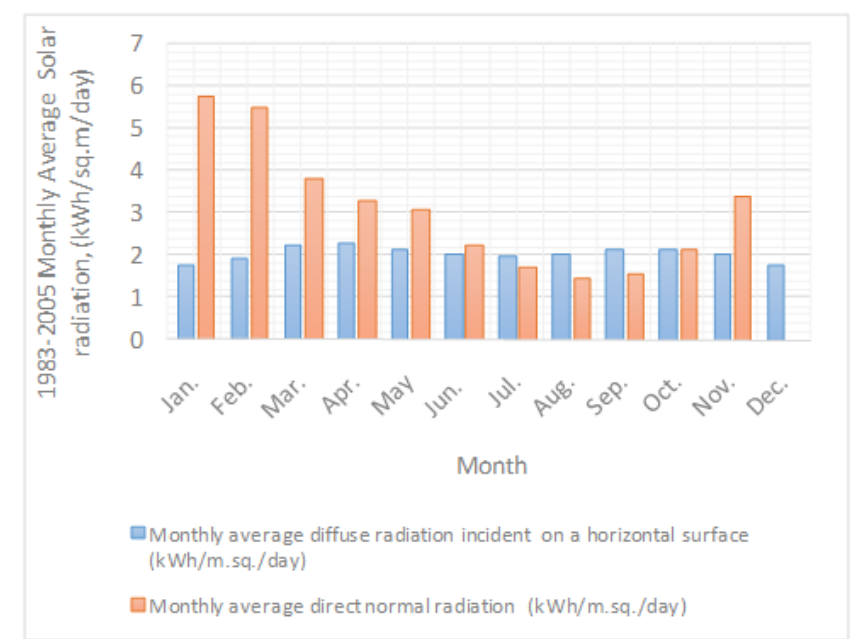

Figure 2: Average monthly solar radiation sourced from (https://eosweb.larc.nasa.gov/)

However, the output power from photovoltaic solar panels is not constant but varies with time of day, geographical location and inclination or tilting angle [5,6]. The effects of these factors must be studied in the design and planning of an efficient and reliable solar power system. There is a need to evaluate or measure the inclination of the PV cells, so as to maximize the solar output, which is site dependent [7]. Hence, this paper will investigate the variation of PV output voltage with time. We present a review of some studies on solar PV angles and power output.

Gizon and Solanki [8] observed that inclination angle can be obtained when the angle between the line of sight and the direction of the rotation axis of a pulsating sun-like star is greater or equal to $30^{\circ}$ for rotating star twice as fast as the sun. Meanwhile, Li and Lam [9] used prediction method to evaluate the solar radiation received of a solar PV inclined at $22.3^{0}$ south oriented surface, being the latitude of the research location Hong Kong. This can provide alternative solution in determining the amount of radiation on inclined surface facing various orientation when the sky radiance data are available. Karimov, et al [10] described a photovoltaic tracking system developed using a base pyramidal stand. The system consists of two pairs of modules fixed at $170^{\circ}$ apart installed at the upper edge of the pyramidal stand. The inclination angle between the horizontal plane and the modules is around $23^{\circ}-45^{\circ}$ with $120^{\circ}$ tracking angle. Whereas, the annual solar radiation at various sloped surface facing different orientations and monthly solar radiations at the optimal tilt surface and vertical planes facing east, south and west respectively were obtained in [11].

In a review of principles and sun-tracking methods for optimizing received solar energy, Mousazadeh, et al [6] pointed out that using sun-tracker have the ability to boost the collected solar energy $10-100 \%$ depending on time period and geographical condition. However, the authors did not recommend solar tracker for small scale solar power systems due to the expected $2-3 \%$ of the increased energy lost in driving the tracker system.

On the other hand, Shademan and Hangan [12] used computational fluid dynamics (CFD) simulation to estimate the wind load for various wind direction on stand-alone and arrayed solar panel. Conceptually, CFD is an aspect of fluid mechanics, which performs analysis problems of fluid flow using numerical analysis and procedures. While acknowledging that solar radiation depends on latitude, season and time of the day, Calabro [5] used archival solar data in Italy to determines sets of optimal tilt angle for winter and summer months. Tao, et al [13] developed a system aimed at addressing the problem of caused by fluctuation and intermittence of photovoltaic cell power output. This thus, emphasizes the need to determine photovoltaic cell inclination angle. Whereas, Notton, et al [14] observed that the PV inclination angle affects the performance of solar power system especially when the inverter is undersized in comparison with the PV peak power.

Furthermore, optimization of tilt angle for solar panel was carried out in [15], where it was assumed that the collector surface is facing the equator. The study used measured daily global and diffuse solar radiation on a horizontal surface for its analysis. The results obtained showed that the annual optimum tilt angle is around the latitude of the location. Systems using optimal tilt angle can prevent $8 \%$ loss in yearly average solar power as against system with implementing solar panel with fixed angle.

A reviewed solar optimum tilt angle studies was carried out by Yadav and Chandel [7] emphasized that tilt angle is unique to site. Tahani, et al [16] investigated optimum translocation of solar panels so as to capture the maximum solar power and controlling the wind direction for obtaining the maximum energy from wind turbine. It uses particle swarm optimization technique. It reported that for maximum solar power, the panel tilt must be around $30^{\circ}$. 
The rest of this paper is arranged as follows: section 2 presents household energy consumption patterns for three income classes. Whereas, section 3 highlights the methodology for the PV experimentations. The results obtained were shown and discussed in section 4. And finally, conclusion reached and suggested recommendation were reported in section 5 .

\section{Household Energy consumption}

For a typical household having $N$ appliances, typical energy consumption pattern is shown in Table 1, where LC is lower income class household, MC is middle income class household and UC is upper income class household. When $N_{i}$ is the units of appliances with rated power $P_{r}$ operating for $H$ hours, own by the householder, then the total energy consumable is evaluated using equation 1.The pie chart of Figure 3 shows pictorially the consumption pattern of these income classes in Nigeria.

$$
E_{h i}=N_{i} \times P_{r} \times H
$$

Table 1: Estimated average Nigerian household load consumption data

\begin{tabular}{|c|c|c|c|c|c|c|c|c|}
\hline \multirow[t]{2}{*}{ Appliances, $i$} & \multicolumn{3}{|c|}{ Quantity, $N_{i}$} & \multirow[t]{2}{*}{ power, $P_{r}(\mathrm{kw})$} & \multirow[t]{2}{*}{$\begin{array}{l}\text { Hours of use per } \\
\text { day, } H \text { (h) }\end{array}$} & \multicolumn{3}{|c|}{$\begin{array}{l}\text { Energy } \\
E_{h i}=N_{i} \times P_{r} \times H(\mathrm{kWh})\end{array}$} \\
\hline & $\mathrm{LC}$ & $\mathrm{MC}$ & $\mathrm{UC}$ & & & LC & $\mathrm{MC}$ & $\mathrm{UC}$ \\
\hline Energy saving bulbs & 0 & 5 & 9 & 0.010 & 6 & 0 & 0.300 & 0.540 \\
\hline TV (LCD, LED, etc.) & 0 & 1 & 2 & 0.020 & 8 & 0 & 0.160 & 0.320 \\
\hline Fans & 1 & 4 & 6 & 0.042 & 6 & 0.252 & 1.008 & 1.512 \\
\hline Air conditioner & 0 & 0 & 2 & 1.200 & 2 & 0 & 0 & 4.800 \\
\hline Oven/Microwave & 0 & 1 & 1 & 1.000 & 1 & 0 & 1.000 & 1.000 \\
\hline Electric cooker & 0 & 2 & 4 & 0.750 & 3 & 0 & 4.500 & 9.000 \\
\hline Electric kettle & 0 & 1 & 1 & 2.000 & 0.5 & 0 & 1.000 & 1.000 \\
\hline Water pumps & 0 & 0 & 1 & 1.500 & 2 & 0 & 0 & 3.000 \\
\hline Laptops/Desktop & 0 & 1 & 2 & 0.065 & 3 & 0 & 0.195 & 0.390 \\
\hline Mobile phone chargers & 2 & 3 & 5 & 0.005 & 3 & 0.030 & 0.045 & 0.075 \\
\hline Dish washers & 0 & 0 & 1 & 0.120 & 1 & 0 & 0 & 0.120 \\
\hline Clothe washing machines & 0 & 1 & 1 & 0.600 & 1 & 0 & 0.600 & 0.600 \\
\hline Refrigerator & 0 & 1 & 2 & 0.300 & 8 & 0 & 2.400 & 4.800 \\
\hline Deep freezer & 0 & 0 & 1 & 0.500 & 8 & 0 & 0 & 4.000 \\
\hline Printer/Scanner & 0 & 1 & 1 & 0.010 & 1 & 0 & 0.010 & 0.010 \\
\hline Pressing iron & 1 & 1 & 1 & 1.200 & 1 & 1.200 & 1.200 & 1.200 \\
\hline 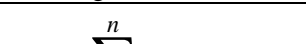 & & & & & & 4.423 & 15.467 & 46.520 \\
\hline
\end{tabular}

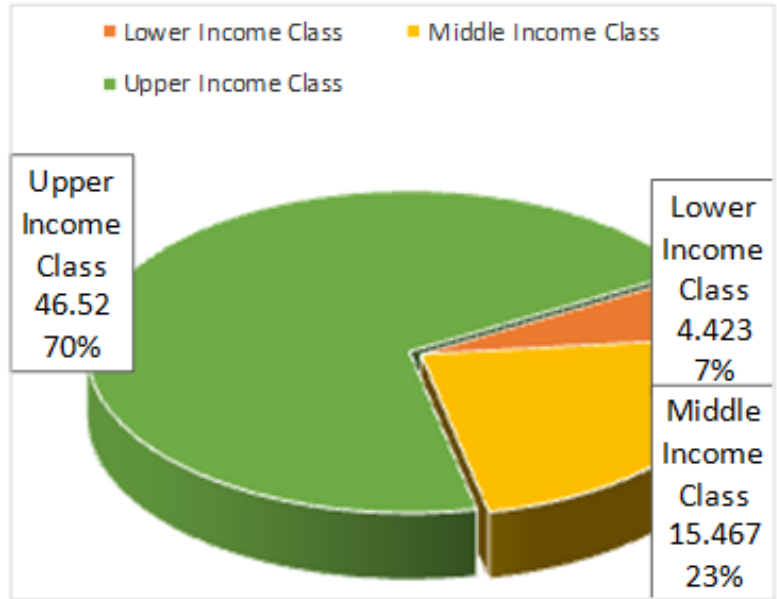

Figure 3: Energy consumption pattern among income classes 
The following parameters affecting solar power output such as angle of incidence, temperature and solar radiation were analyzed in [17]. It consequently design a PV systems that will operate more efficiently and experimentally studied a system tracking solar radiation in two axes and in a fixed system. Figure 4 shows azimuthal, zenith and hour angles for solar radiation evaluation. Figure 5 shows recommended mounting angles for fixed solar collectors.

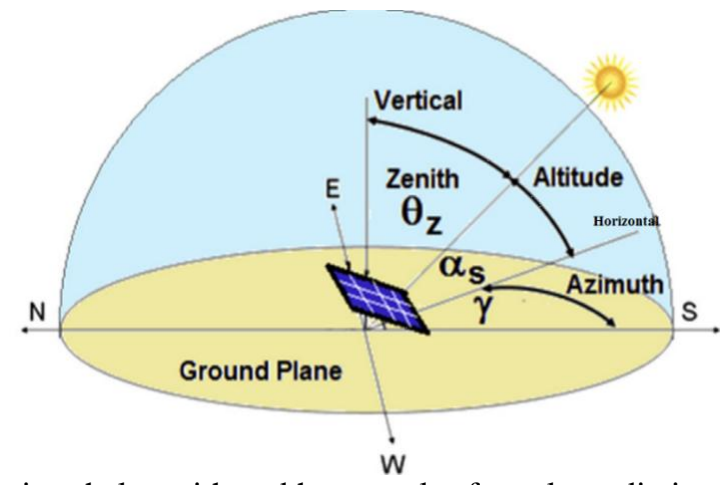

Figure 4: Azimuthal, zenith and hour angles for solar radiation evaluation

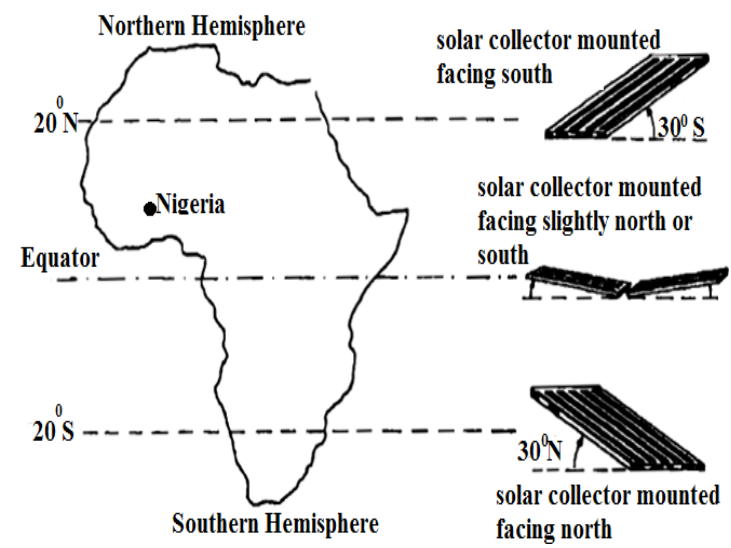

Figure 5: Mounting angles for fixed solar collectors, adapted from [3]

A brief discussion of the various angles in solar panel installation is presented next [17]:

The angle between the solar radiation and the horizon is called Elevation angle $\left(\alpha_{s}\right)$, while, solar azimuth angle $\left(\gamma_{s}\right)$ is the angle showing the tilt of sun's rays to the north in the clockwise direction. Surface azimuth angle $(\gamma)$ is the angle showing the deviation of the vertical surface to the local longitude for the surfaces facing south. It takes positive values for the surface facing to the east. It has negative values for the westward surface. Whereas, the declination angle $(\delta)$ is the angle between equatorial plane and sun's rays at 12 o'clock. The angle between the normal of the surface and the sun's rays is the incidence angle $(\theta)$.

Zenith angle $\left(\theta_{z}\right)$ is the angle between the beam and the normal of the horizontal surface. Latitude angle $(\phi)$ takes positive values in the Northern Hemisphere. Moreover, clock angle $(\omega)$ takes negative values before noon. They become zero at noon and positive after 12 o' clock. Inclination angle $(\beta)$, also known as tilt angle is the angle between the surface and horizon. Its value is positive for the surface facing to the equator. The zenith angle is related to the elevation angle according to equation 2.

$$
\alpha_{s}+\theta_{z}=90^{\circ}
$$

From [18], tilt angle is related to latitude according to equation 3.

$$
\beta=0.9 \phi+\text { season angle }
$$




\section{Material and Methods}

This work examined the effect of varying inclination angle of photovoltaic cell installed in Offa. Offa is a town located in Kwara State, North Central, Nigeria, with coordinates: longitudes $8.1393^{\circ} \mathrm{N}$ and latitude $4.7174^{0} \mathrm{E}$. The steps used involves;

$\sim$ Setting the photovoltaic cell inclined at angle $\beta,\left(0^{0} \leq \beta \leq 90^{\circ}\right)$,

$\sim$ Measure the output voltage using a digital voltmeter,

$\sim$ Recording the result obtained,

$\sim$ Choose a new $\delta$ and repeat the above procedure, until $\beta=90^{\circ}$.

The experimentation of the effect of inclination angle on PV output voltage was done within a short time period so as to avoid the effect of time variation.

The second stage of the study was the examination of PV voltage variations with time of day over a seven-day period. A 150 watts solar panel was used in the experimentations. The solar PV characteristics parameters are shown in Table 2.

Table 2: Solar PV characteristics

\begin{tabular}{|l|l|l|}
\hline Product Name & Voltage Level & Rated current \\
\hline Wagan Monolithic & Rated $=17.8 \mathrm{~V} ;$ & Open circuit $=58.4 \mathrm{~mA} ;$ \\
Solar & Peak $=20.4 \mathrm{~V}$ & Short circuit $=15 \mathrm{~A}$ \\
\hline
\end{tabular}

Data was sourced from National Aeronautic Space agency atmospheric science data center website (https://eosweb.larc.nasa.gov). The results are shown in Figure 2 and 6.

The variation of solar PV during a daytime hours over seven-day period was observed and the results obtained were recorded and presented in Figure 7-13.

\section{Discussions}

The result obtained is shown in Table 3. It is presented as a percentage of the rated voltage of the solar panel. The related voltage is equal to $20 \mathrm{~V}$.

Table 3: photovoltaic output voltage variation with inclination angle

\begin{tabular}{|l|l|l|l|l|l|l|l|l|l|l|}
\hline $\begin{array}{l}\text { Angle of inclination in } \\
\text { degree, } \beta\end{array}$ & 0 & 10 & 20 & 30 & 40 & 50 & 60 & 70 & 80 & 90 \\
\hline Output voltage, volts & 17.4 & 18.6 & 19.4 & 20.0 & 20.0 & 19.6 & 18.8 & 17.6 & 16.0 & 12.8 \\
\hline $\begin{array}{l}\% \text { of Maximum } \\
\text { voltage obtained }\end{array}$ & 87 & 93 & 97 & 100 & 100 & 98 & 94 & 88 & 80 & 64 \\
\hline
\end{tabular}

The highest PV voltage output was obtained at $\beta=30^{\circ}$ to $40^{\circ}$. While the lowest PV voltage output was seen at inclination angle equal to $90^{\circ}$. However, the estimated radiation at selected tilt angle is shown in Figure 6.

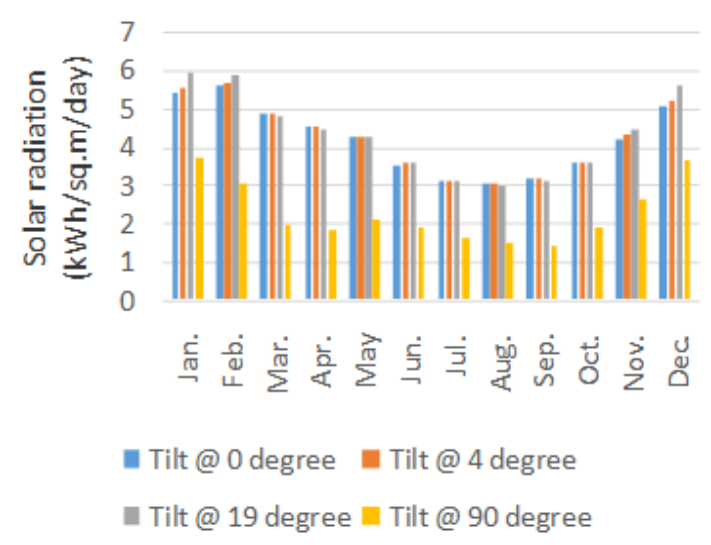

Figure 6: Average monthly solar radiation at various tilt angle sourced from (https://eosweb.larc.nasa.gov/cgi$\mathrm{bin} / \mathrm{sse})$ 


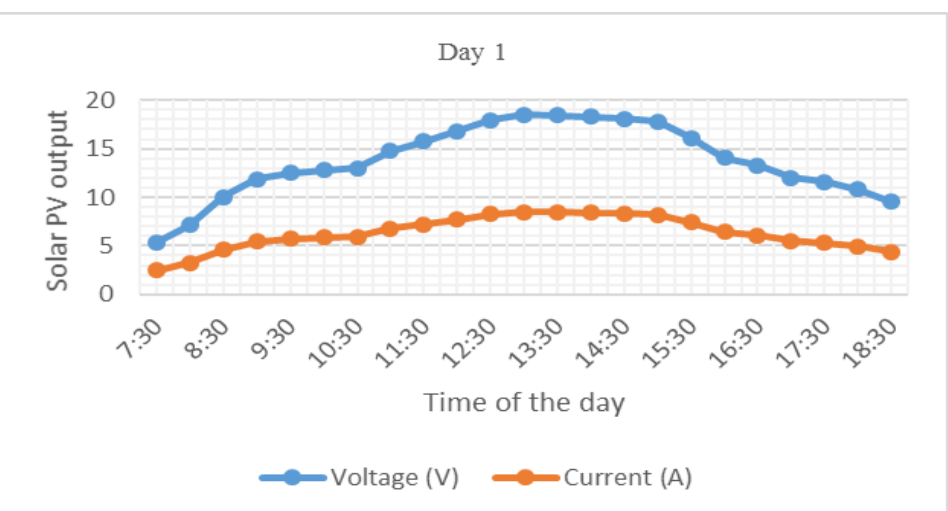

Figure 7: Variations of voltage and current of solar PV for Day 1

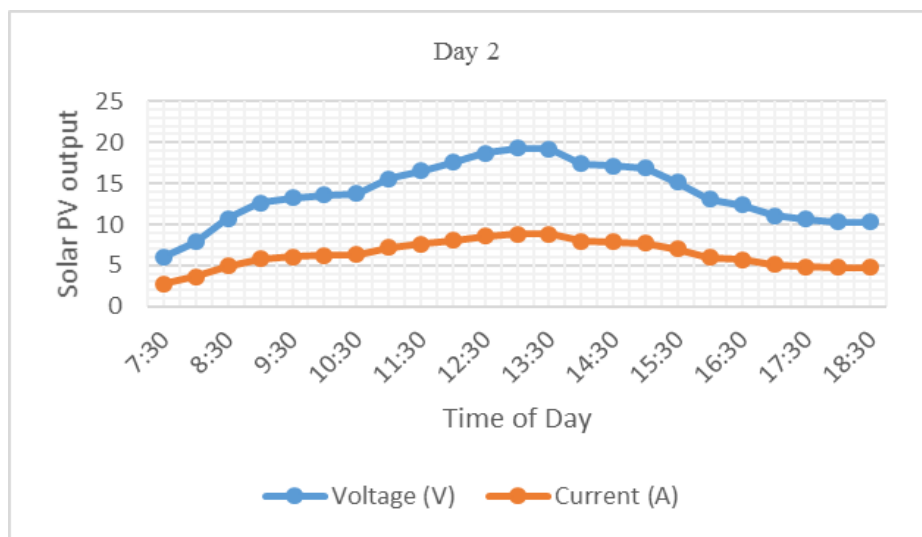

Figure 8: Variations of voltage and current of solar PV for Day 2

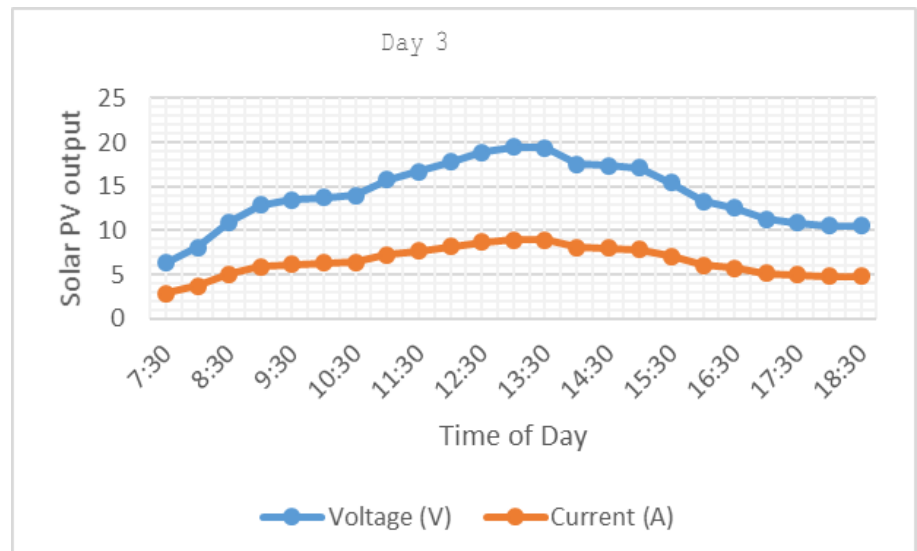

Figure 9: Variations of voltage and current of solar PV for Day 3

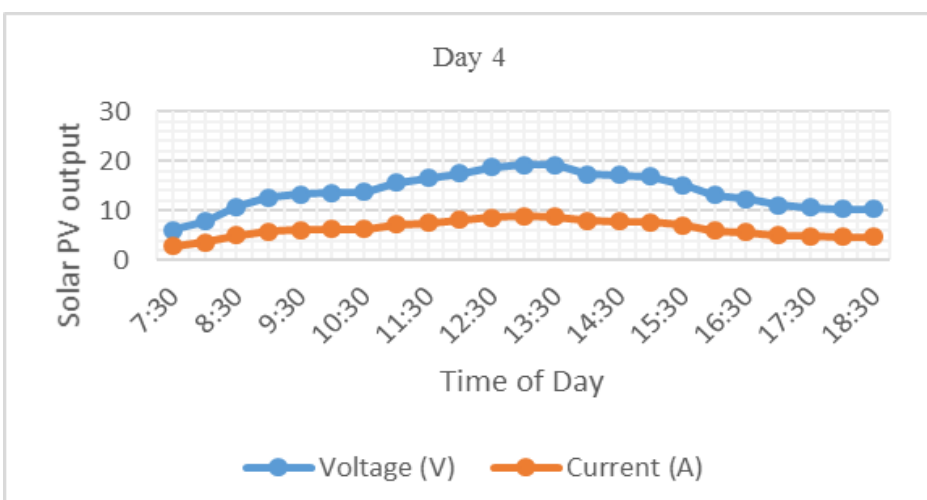

Figure 10: Variations of voltage and current of solar PV for Day 4 


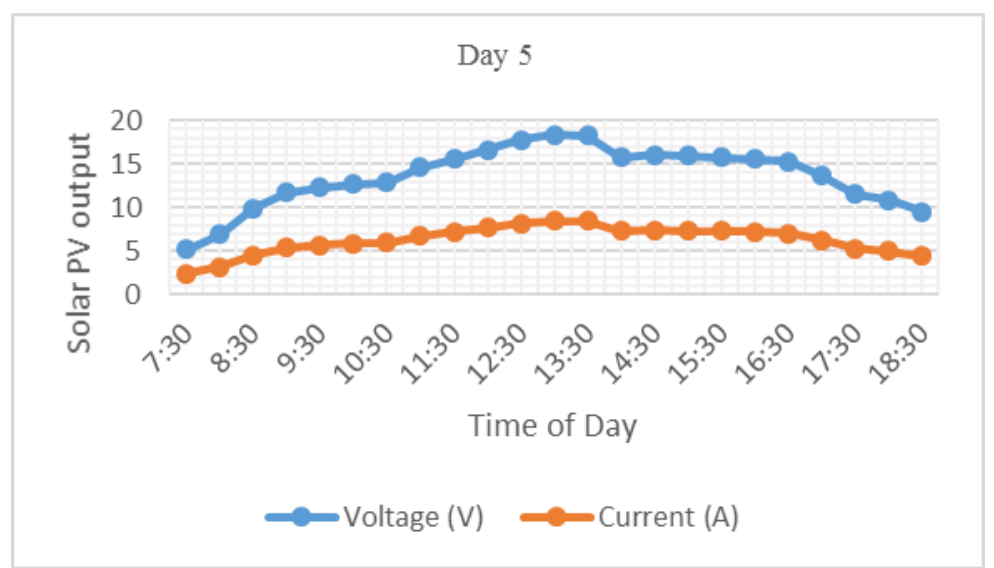

Figure 11: Variations of voltage and current of solar PV for Day 5

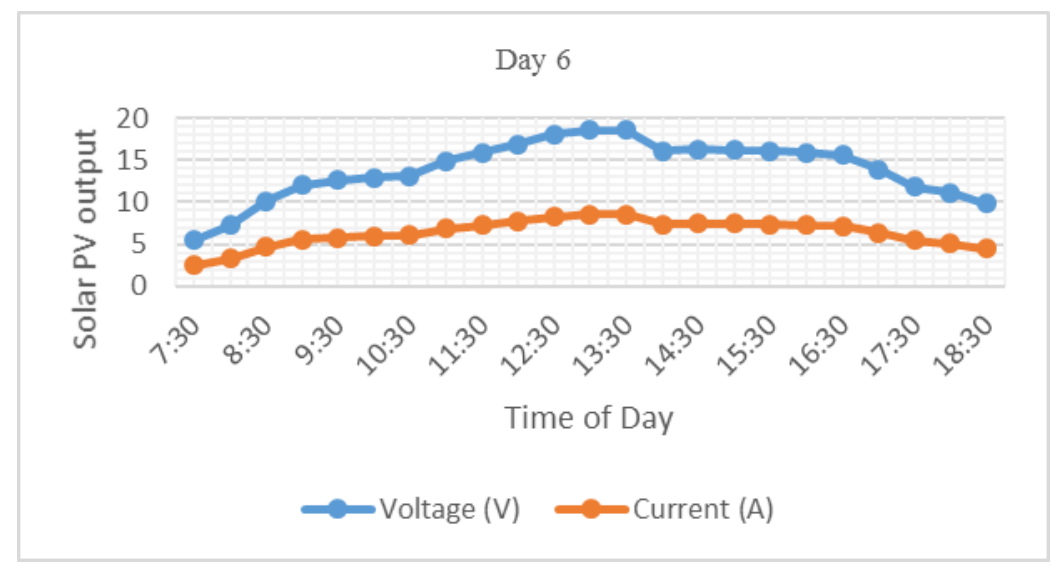

Figure 12: Variations of voltage and current of solar PV for Day 6

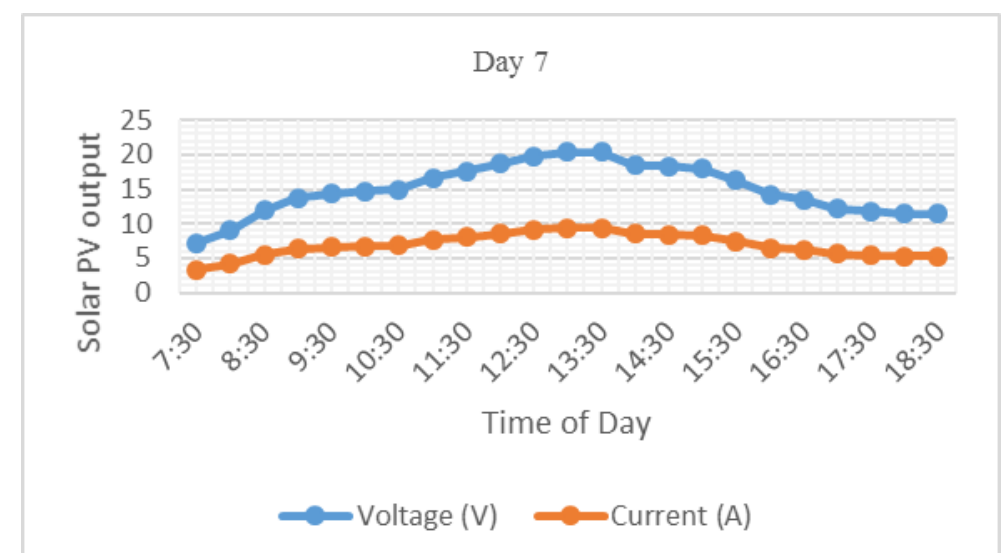

Figure 13: Variations of voltage and current of solar PV for Day 7

From the plot the highest voltage and current readings were obtained at around 13:00-13:30.

\section{Conclusion and Recommendations}

The research found out that the best tilt angle for Offa, Nigeria is around $30^{\circ}-40^{\circ}$. This seems to tally with data obtained from National Aeronautic Space agency atmospheric science data center website (https://eosweb.larc.nasa.gov), which was shown in Figure 6. It shows a plot of $0^{0}, 4^{0}, 19^{0}$ and $90^{\circ} \mathrm{PV}$ tilt angles against solar radiation in $\mathrm{kWh} / \mathrm{m}^{2}$. The highest solar radiation was receive at $19^{0}$.

The results obtained from the study of PV voltage variation with time shown in Figure 7-13 indicates that the highest voltage was obtained at about 13:00-13:30 hours. For lower and middle income energy consumers there would be no need for solar tracker. However, they should install their PV panels at $30^{\circ} \leq \beta \leq 40^{\circ}$. Moreover, for higher income consumer and commercial user, there may be need to incorporate 
low power solar tracker into the solar PV power system. This articles also presented household load patterns for low, middle and upper income class in Nigeria. These finding should be considered when designing solar power system for domestic and office use. However, further study can be directed to investigating the tilt angle for various seasons such as raining, dry, and "Harmattan" seasons. The effect of dust films on PV panel received solar radiation also need to be examined.

\section{References}

[1]. M. S. Okundamiya and O. Omorogiuwa, "Viability of a Photovoltaic-diesel-battery hybrid power system in Nigeria," Iranica Journal of Energy and Environment, vol. 6, no. 1, pp. 5-12, 2015.

[2]. M. A. Rosen, "Energy sustainability: A pragmatic approach and illustartion," Sustainability, vol. 1, pp. 55-80, 30 March 2009.

[3]. O. Awogbemi, I. O. Oluwaleye and C. A. Komolafe, "A survey of solar energy utilization for sustainable development in Nigeria," Journal of Multidisciplinary Engineering Science and Technology, vol. 2, no. 7, pp. 1716-1724, 2015.

[4]. K. Solangi, M. Islam, R. Saidur, N. Rahim and H. Fayaz, "A review on global solar energy policy," Renewable and Sustainable Energy Reviews, vol. XV, p. 2149-2163, 2011.

[5]. E. Calabro, "Determining optimum tilt angles of photovoltaic panels at typical north-tropical latitude," Journal of Renewable and Sustainable Energy, vol. 1, no. 3, p. 033104, 2009.

[6]. H. Mousazadeh, A. Keyhani, A. Javadi, H. Mobli, K. Abrinia and A. Sharifi, "A review of principle and sun-tracking methods for maximizing solar systems output," Renewable and Sustainable Energy Reviews, vol. 13, pp. 1800-1818, 2009.

[7]. A. K. Yadav and S. S. Chandel, "Tilt angle optimization to maximize incident solar radiation: A review," Renewable and Sustainable Energy Reviews, vol. 23, pp. 503-513, 2013.

[8]. L. Gizon and S. K. Solanki, "Determining the inclination of the rotation axis of a sun-like star," The Astronophysical Journal, vol. 589, no. 2, p. 1009, 2003.

[9]. D. H. Li and J. C. Lam, "Predicting solar irradiance on inclined surfaces using sky radiance data," Energy Conversion Management, vol. 45, no. 11, pp. 1771-1783, 2004.

[10]. K. S. Karimov, M. A. Saqib, P. Akhter, M. M. Ahmed, J. A. Chatta and S. A. Yousafzai, "A simple photo-voltaic tracking system," Solar energy materials and solar cells, vol. 87, no. 1, pp. 49-59, 31 May 2005.

[11]. D. H. W. Li and T. N. T. Lam, "Determining the optimum tilt angle and orientation for solar energy collection based on measured solar radiance data," International Journal of Photoenergy, vol. 2007, 2007.

[12]. M. Shademan and H. Hangan, "Wind loading on solar panels at different inclination angle," in 11th Conference of American Society of Wind Engineers, San Juan, Puerto Rico, 2009.

[13]. C. Tao, D. Shanxu and C. Changsong, "Forecasting power output for grid-connected photovoltaic power system without using solar radiation measurement," in Power Electronics for Distributed Generation Systems (PEDG), 2010 2nd IEEE International Symposium on, 2010.

[14]. g. Notton, V. Lazarov and L. Stoyanov, "Optimal sizing of a grid-connected PV system for various PV module technologies and inclinations, inverter efficiency characteristics and locations," Renewable Energy, vol. 35, no. 2, pp. 541-554, 2010.

[15]. M. Benghanem, "Optimization of tilt angle for solar panel: case study for Madinah, Saudi Arabia," Applied Energy, vol. 88, no. 4, pp. 1427-1433, 30 April 2011.

[16]. M. Tahani, N. Babayan, A. Pouyaei, M. Mirhosseini and A. Sedaghat, "Increasing the produced power of building mounted wind turbines by optimazation of roof geometry and utilization of solar panels," in 2015 International Conference on Sustainable Mobility Applications, Renewables and Technology (SMART), 2015

[17]. S. Yilmaz, H. Riza, O. Ozcalik, F. Dincer, O. Akgol and O. Karaaslan, "Design of two axes sun tracking controller with analytically solar radiation calculation," Renewable and Sustainable Energy Review, vol. 43, pp. 997-1005, March 2015.

[18]. S. K. Sakiliba, A. S. Hassan, J. Wu, E. S. Sanneh and S. Ademi, "Assessment of stand-alone residential solar photovoltaic application in Sub-Saharan Africa: A case study of Gambia," Journal of Renewable Energy, pp. 1-10, October 2015. 